\title{
Direct Carbon Isotope Exchange of Pharmaceuticals via Reversible Decyanation
}

\author{
Minghao Feng, ${ }^{\dagger}$ Joao De Oliveira, ${ }^{\dagger, \pi}$ Antoine Sallustrau, ${ }^{\dagger}$ Gianluca Destro, $,{ }^{\dagger}, \dot{\phi}$ Pierre Thuéry,${ }^{\ddagger}$ \\ Sebastien Roy, ${ }^{\mathbb{T}}$ Thibault Cantat,${ }^{\ddagger}$ Charles S. Elmore, ${ }^{\S}$ Jorg Blankenstein, ${ }^{\mathbb{T}}$ Frédéric Taran, ${ }^{\dagger}$ \\ Davide Audisio ${ }^{\dagger *}$

\footnotetext{
${ }^{\dagger}$ Université Paris Saclay, Service de Chimie Bio-organique et Marquage (SCBM), CEA/DRF/JOLIOT, Gif-surYvette, France.

‡ Université Paris Saclay, CEA, CNRS, NIMBE, 91191 Gif-sur-Yvette, France.

$\S$ Isotope Chemistry, Pharmaceutical Science, R\&D, AstraZeneca, 43183, Gothenburg, Sweden.

"Isotope Chemistry, Integrated Drug Discovery Sanofi R\&D, Vitry-sur-Seine, France.
}

\begin{abstract}
The incorporation of carbon-14 allows tracking of organic molecules and provides vital knowledge on their fate. This information is critical in pharmaceutical development, crop science and human food safety evaluation. Herein, a transition-metal-catalyzed procedure enabling carbon isotope exchange on aromatic nitriles is described. Utilizing the radiolabeled precursor $\mathrm{Zn}\left(\left[{ }^{14} \mathrm{C}\right] \mathrm{CN}\right)_{2}$, this protocol allows the insertion of the desired carbon tag without need of structural modifications, in a single step. Reducing synthetic costs and limiting the generation of radioactive waste, this procedure will facilitate the labeling of nitrile containing drugs and accelerate ${ }^{14} \mathrm{C}$-based ADME studies supporting drug development.
\end{abstract}

Humans are surrounded by a dazzling array of synthetic organic molecules. Their impact on improving life quality and lifestyle is beyond doubt. Thus, it is of fundamental importance to accurately detect and quantify the fate of organic compounds and provide a precise risk/benefit assessment before they reach the market and large public exposure. The seemless incorporation of carbon-14 tracer $\left({ }^{14} \mathrm{C}, \beta^{-}\right.$emitter, $\mathrm{t}_{1 / 2}=5730$ years $)$ is a technology recognised as the gold standard. ${ }^{1,2}$

${ }^{14} \mathrm{C}$ radiolabeling is indeed a unique tool that, in association with ?-counting and ?-imaging technologies, provides vital knowledge on the fate of synthetic organic molecules. ${ }^{3,4}$ This information is critical to assess potential issues affecting human health and is required worldwide by regulatory agencies for: i) crop science and environmental fate studies, ii) human food safety evaluation and iii) human and veterinary pharmaceutical development to unveil drug absorption, distribution, metabolism and excretion (ADME) and pharmacokinetic properties of novel pharmaceuticals (Fig $1 \mathrm{~A}$ ). ${ }^{5} \mathrm{~A}$ rapid and straightforward synthetic access to carbon radiolabeled organic molecules is a strict requirement for accelerating research in these societal impacting fields. However, carbon radiosynthesis surprisingly still represents a major bottleneck and a fundamental problem. The energetic barrier required for carboncarbon bond formation and the rare ${ }^{14} \mathrm{C}$-bulding blocks available are major obstacles. ${ }^{6,7}{ }^{14} \mathrm{C}$ - 
building blocks are classicaly used in a multi-step fashion and the radioactivity is incorporated into the chemical scaffold at an early stage of the synthesis (Fig. 1C). ${ }^{8}$ This approach is marred by several drawbacks: $i$ ) the generation of radioactive waste (extremely difficult and expensive to dispose of); ii) the multi-step, time-consuming nature of such approaches mandates the development of a specific route in line with the radio-synthetic requirements and safety regulations; iii) high resource-demanding: the price for $37 \mathrm{GBq}$ of $\mathrm{Ba}\left[{ }^{14} \mathrm{C}\right] \mathrm{CO}_{3}$ (ca. $3.3 \mathrm{~g}$ ), the cheapest source of ${ }^{14} \mathrm{C}$ is $25 \mathrm{k} €$. Other starting materials require additional synthetic steps and costs increase dramatically with each additional step.

Recent examples of late-stage ${ }^{14} \mathrm{C}$ incorporation allow insertion of the label in the last-step of the synthesis, but they require the elaboration of functionalized precursors. ${ }^{9}$ Isotope exchange is a promising concept. The selective replacement of molecular moieties into organic molecules, by reversible deconstruction/reconstruction in presence of an appropriate radiolabeled moiety, enables the access to labeled compounds in a single operation, directly from the end-use molecules. Isotope exchange has only recently emerged for carbon radiolabeling ${ }^{10}$ and it is thus far limited to carboxylic acids using $\left[{ }^{14} \mathrm{C}\right] \mathrm{CO}_{2}{ }^{11,12,13,14}$ and $\left[{ }^{14} \mathrm{C}\right] \mathrm{CO} .{ }^{15}$ Herein, we propose a solution for fast radiolabeling that is based on a reversible decyanation/cyanation procedure to enable nitrile $\left({ }^{14} \mathrm{CN}\right)$ incorporation into pharmaceuticals by means of transition-metal catalysis.
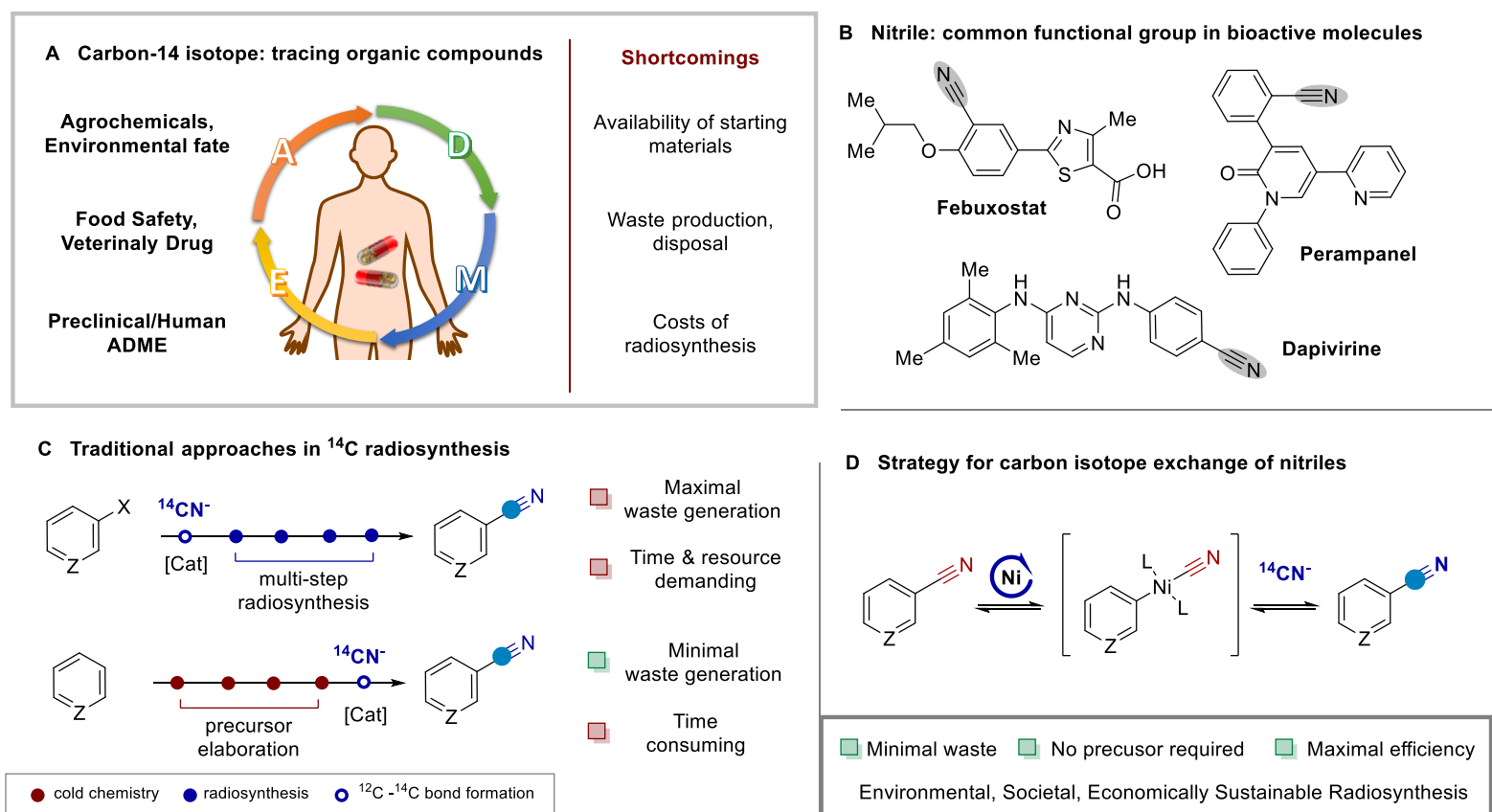

Fig. 1. Development of nitrile carbon isotope exchange. (A) societal field impacted by routine ${ }^{14} \mathrm{C}$-radiosynthesis of organic compounds. (B) representative examples of bioactive molecules bearing nitrile moieties. (C) Multisteps approaches commonly utilized to insert ${ }^{14} \mathrm{C}$-nitriles into biologically relevant molecules. (D) Nitrile carbon isotope exchange. The blue colored circles denote the positions of the labeled carbon atoms. 
Nitriles are versatile synthetic intermediates, precursors to amines, carboxylic acids, carboxamides, aldehydes, ketones and alcohols. ${ }^{16}$ Besides its malleability as a functional group, the nitrile moiety is present on a number of natural products and pharmaceuticals ${ }^{17}$ thus representing a valuable and yet versatile architectural element for labeling (Fig 1B). ${ }^{18}$ Metal $\left[{ }^{14} \mathrm{C}\right]$ cyanides $(\mathrm{M}=\mathrm{Na}, \mathrm{K}, \mathrm{Zn})$ are among the most versatile reagents in ${ }^{14} \mathrm{C}$ synthesis. They are available commercially at reasonable price or can be prepared with relative ease. Their easier manipulation, compared to gaseous sources such as $\left[{ }^{14} \mathrm{C}\right] \mathrm{CO}_{2}$ and $\left[{ }^{14} \mathrm{C}\right] \mathrm{CO}$, makes $\left[{ }^{14} \mathrm{C}\right]$ cyanides the most utilized building blocks in ${ }^{14} \mathrm{C}$ radiosynthesis. ${ }^{6,18}$

We recognised that access to a late-stage, functional group tolerant carbon isotope exchange (CIE) reaction of (hetero)aryl nitriles would be attractive and increase the chemical space available for direct ${ }^{14} \mathrm{C}$-labeling. Such technology would enable straightforward access to ${ }^{14} \mathrm{C}$ nitrile radiotracers and a more sustainable radiocarbon synthesis. To bridge this gap, one would need to selectively break a stable ${ }^{12} \mathrm{C}-{ }^{12} \mathrm{CN}$ bond (C-CN bond dissociation energy 130 $\mathrm{kcal} / \mathrm{mol})^{19}$ and create a new ${ }^{12} \mathrm{C}-{ }^{14} \mathrm{CN}$ bond with a radiolabeled source of nitrile.

In contrast to the activation of aryl halides, routinely performed under palladium catalysis, the oxidative addition of C-CN bonds often required the use of low-valent nickel species. ${ }^{20,21}$ On the other hand, metal cyanides are known to transmetalate on organometallic metal species (with $\mathrm{Ni}, \mathrm{Pd}$ and $\mathrm{Pt}$ ). ${ }^{22,23}$ Based on these precedents, the hypothesis of nitrile CIE seemed reasonable and should allow isotopic nitrile metathesis in presence of suitable labeled $\mathrm{CN}^{-}$ sources. $^{24}$

Based on this hypothesis, preliminary studies conducted on model nitrile 1, rapidly confirmed that isotope exchange proceeded successfully (Fig. 2A). In presence of $\mathrm{Ni}(\mathrm{COD})_{2}(40 \mathrm{~mol} \%)$, trimethylphosphine $\mathrm{PMe}_{3}$ (2 equiv.) and DMAP (1.3 equiv.) in refluxing toluene, cyanide metathesis was optimal with stable $\mathrm{Zn}\left(\left[{ }^{13} \mathrm{C}\right] \mathrm{CN}\right)_{2}$ ( 0.65 equiv. corresponding to 1.3 equiv. of $\left.\left[{ }^{13} \mathrm{C}\right] \mathrm{CN}^{-}\right)$as isotopic source. Labeled nitrile $\left[{ }^{13} \mathrm{C}\right] 1$ was isolated in $90 \%$ yield and $55 \%$ isotope enrichments, which is in line with the maximal value expected under dynamic conditions. ${ }^{25}$ Variation from the standard conditions afforded either minimal isotope incorporation and inferior isolated yield of $\left[{ }^{13} \mathrm{C}\right] 1 \mathrm{a}$ (Fig. $2 \mathrm{~A}$, and $\mathrm{SI}$ ). Alternative cyanide sources proved ineffective (Fig. 2A, entries 1 and 2 ) and the use of trimethyl phosphine and DMAP were crucial for the optimal cyanide incorporation (Fig. 2A, entries 4 to 6). Lower catalyst loading provided minimal isotope incorporation suggesting catalyst poisoning under the reaction conditions (Fig. 2A, entry 7).. ${ }^{26}$ When the reaction was performed at lower temperature poor isotope enrichment was obtained (Fig. 2A, entry 8 ).

On the basis of these results, we sought to evaluate the generality of the cyanide exchange (Fig. 2B). Variation of substituents on the aromatic group revealed that presence of electronrich methoxy substituents in ortho, meta and para position are compatible, affording the desired products in 78 to $90 \%$ yield and good isotope incorporation. The presence of substituted amines $(\mathbf{6}, \mathbf{7})$, alcohol $(\mathbf{8})$ and poly aromatic derivative (11-13) were tolerated. 


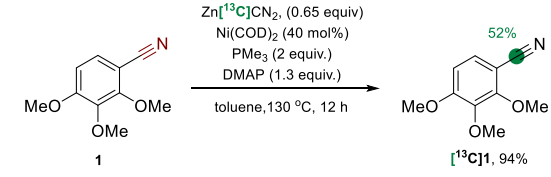

deviation from std. cdtns. $\quad\left[{ }^{13} \mathrm{C}\right] 1 \mathbf{a}$ : yield (\%) $\quad\left[\mathrm{E}(\%)^{\mathrm{a}}\right.$

$\left.\mathrm{Na}^{13} \mathrm{C}\right] \mathrm{CN}$ (1.3 equiv.)

Cu $\left[{ }^{13} \mathrm{C}\right] C N$ (1.3 equiv.)

no DMAP

no $\mathrm{PMe}_{3}$

DPPM instead of $\mathrm{PMe}_{3}$

IMes instead of PMe

$20 \mathrm{~mol} \% \mathrm{Ni}(\mathrm{COD})_{2}$

$80^{\circ} \mathrm{C}$

$\begin{array}{ll}84 & <5 \\ 89 & <5 \\ 95 & 12 \\ 79 & <5 \\ 88 & <5 \\ 31 & 13 \\ 85 & 10 \\ 95 & 15\end{array}$

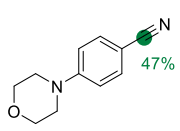

$\left[{ }^{13} \mathrm{C}\right] 7,83 \%$

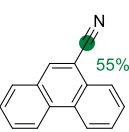

$\left[{ }^{13} \mathrm{C}\right] 13,75 \%$

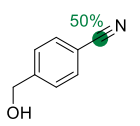

$\left[{ }^{13} \mathrm{C}\right] 8,41 \%$

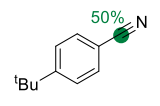

$\left.{ }^{[13} \mathrm{C}\right] 9,72 \%$

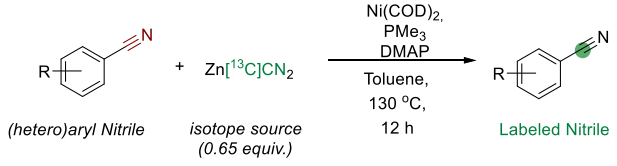

Aryl nitriles
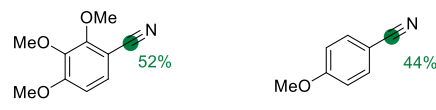

$\left[{ }^{13} \mathrm{C}\right] 2,80 \%$

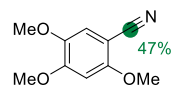

$\left[{ }^{13} \mathrm{C}\right] 1,94 \%$

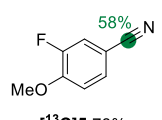

$\left[{ }^{13} \mathrm{C}\right] 5,78 \%$

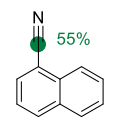

$\left[{ }^{13} \mathrm{C}\right] 11,85 \%$ $\left[{ }^{13} \mathrm{C}\right] 3,81 \%$

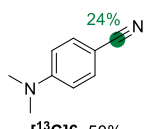

$\left[{ }^{13} \mathrm{C}\right] 6,50 \%$ $\left[{ }^{13} \mathrm{C}\right] 4,83 \%$

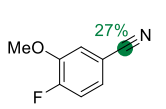

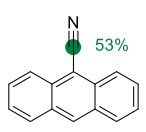

$\left[{ }^{13} \mathrm{C}\right] 12,78 \%$

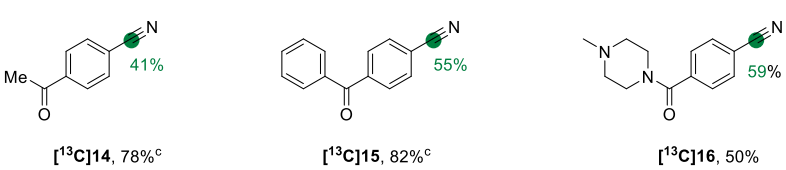

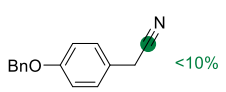

$\left[{ }^{13} \mathrm{C}\right] 17,52 \%$

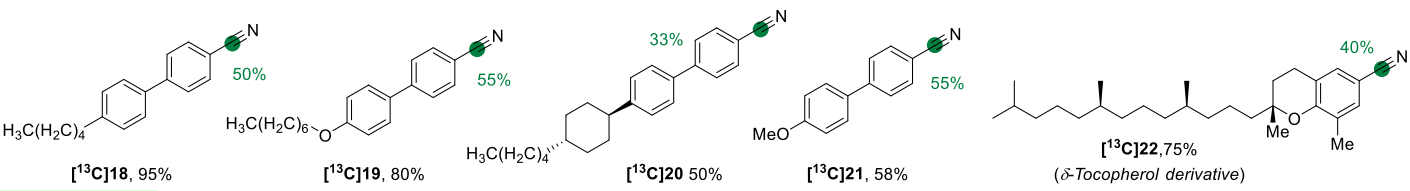

$\left.{ }^{13} \mathrm{C}\right] 19,80 \%$

$\left[{ }^{13} \mathrm{C}\right] 21,58 \%$
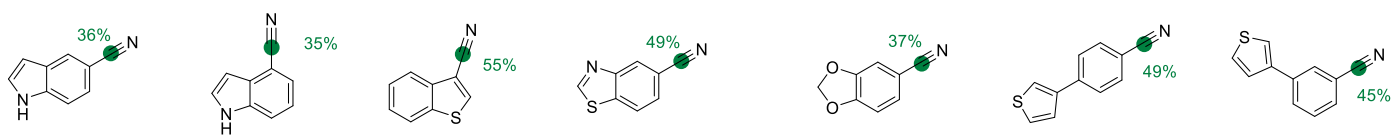

$\left[{ }^{13} \mathrm{C}\right] 23,90 \%$

$\left[{ }^{13} \mathrm{C}\right] 24,71 \%$

$\left[{ }^{13} \mathrm{C}\right] 25,69 \%$

$\left[{ }^{13} \mathrm{C}\right] 26,83 \%$

$\left[{ }^{13} \mathrm{C}\right] 27,72 \%$

$\left[{ }^{13} \mathrm{C}\right] 28,58 \%$

$\left[{ }^{13} \mathrm{C}\right] 29,50 \%$

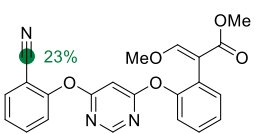

$\left[{ }^{13} \mathrm{C}\right] 30$, Azoxystrobin 42\% (fungicide)

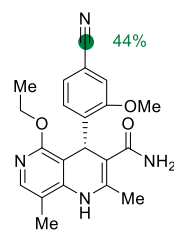

$\left[{ }^{13} \mathrm{C}\right] 34$, Finerenone $74 \%$ (antimineralocorticoid)

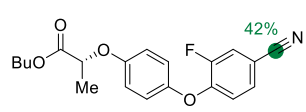

$\left[{ }^{13} \mathrm{C}\right] 31$, Cyhalofop butyl $67 \%$ (herbicide)

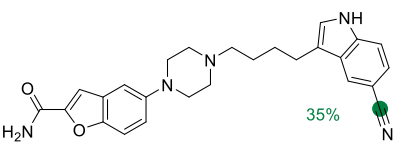

$\left[{ }^{13} \mathrm{C}\right] 35$, Vilazodone $91 \%$ (depressive disorder)
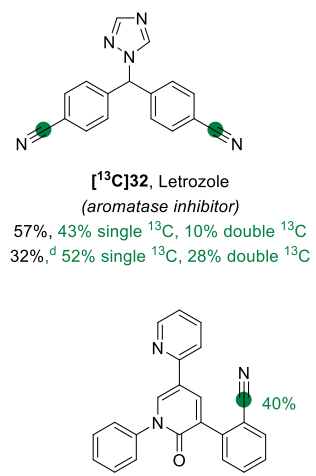

$\left[{ }^{13} \mathrm{C}\right] 36$, Perampanel $87 \%$ (antiepileptic drug)

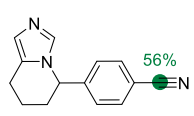

$\left[{ }^{13} \mathrm{C}\right] 33$, Fadrozole $41 \%$ (aromatase inhibitor)

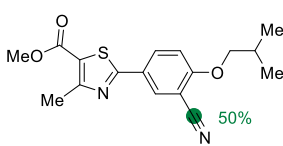

$\left[{ }^{13} \mathrm{C}\right] 37$, Febuxostat ester $61 \%$ (gout treatment)

Fig. 2. Carbon Isotope exchange with nitriles. (A) Deviation from standard conditions. ${ }^{a}$ Isotopic enrichments (IE) were determined by mass spectrometry (see SI for details). Gernal reaction conditions: benzonitrile $(0.10$ $\mathrm{mmol}, 1.0$ equiv.), $\mathrm{Ni}(\mathrm{COD})_{2}(0.040 \mathrm{mmol}, 40 \mathrm{~mol} \%)$, trimethylphosphine $(1.0 \mathrm{M}$ solution in toluene, $0.2 \mathrm{mmol}$, 2.0 equiv.), 4-dimethylaminopyridine $(0.13 \mathrm{mmol}, 1.3$ equiv. $), \mathrm{Zn}\left({ }^{13} \mathrm{CN}\right)_{2}(0.065 \mathrm{mmol}, 0.65$ equiv.), tolene $(0.4$ $\mathrm{mL}), 130^{\circ} \mathrm{C}, 12 \mathrm{~h}$. (B) Scope of the reaction. The colored circles (green) and numbers denote the positions of the carbon atoms labeled and the percent incorporation of the carbon isotope. ${ }^{\mathrm{b}}$ reaction temperature, $120{ }^{\circ} \mathrm{C}$, reaction time $6 \mathrm{~h} .{ }^{\mathrm{c}}$ reaction time $8 \mathrm{~h} .{ }^{\mathrm{d}}$ benzonitrile $\left(0.10 \mathrm{mmol}, 1.0\right.$ equiv.), $\mathrm{Ni}(\mathrm{COD})_{2}(0.080 \mathrm{mmol}, 80 \mathrm{~mol} \%)$, trimethylphosphine (1.0 M solution in toluene, $0.4 \mathrm{mmol}, 4.0$ equiv.), 4-dimethylaminopyridine $(0.26 \mathrm{mmol}, 2.6$ equiv.), $\mathrm{Zn}\left({ }^{13} \mathrm{CN}\right)_{2}\left(0.13 \mathrm{mmol}, 1.3\right.$ equiv.), toluene $(0.2 \mathrm{~mL}), 130{ }^{\circ} \mathrm{C}, 12 \mathrm{~h}$. 
While ketone derivatives were tolerated $(\mathbf{1 4}, \mathbf{1 5})$ with no formation of corresponding cyanohydrins, substrate $\mathbf{1 0}$ with electron-poor fluoride in para position was ineffective under standard conditions. The requirement of milder temperature conditions allowed to isolate $\left[{ }^{13} \mathrm{C}\right] 10$ in $50 \%$ yield and $27 \% \mathrm{IE}$. Commonly used nematic liquid crystal $\left[{ }^{13} \mathrm{C}\right] 18$ was successfully obtained in high yield and $50 \% \mathrm{IE} .{ }^{27}$ The procedure was also successfully applied to the natural product $\delta$ - tocopherol derivative $\left[{ }^{13} \mathrm{C}\right] 22$.

To test the relevance of this procedure, the labeling of important substructures in pharmaceuticals was tested. It was found that the presence of nitrogen-, oxygen- and sulphurcontaining heterocycles was tolerated and substrates 23-29 could be labeled in fair to good enrichment. Next, a series of pharmaceuticals and agrochemicals were labeled in a single step using the nitrile $\mathrm{CIE}$ with good IE (Fig. 2). Esters $\left(\left[{ }^{13} \mathrm{C}\right] 30-31,\left[{ }^{13} \mathrm{C}\right] 37\right)$ worked satisfyingly, as did primary amide $\left(\left[{ }^{13} \mathrm{C}\right] 34\right)$. Pleasingly, a variety of additional heterocycles was compatible, such as 1,2,4-triazole $\left[{ }^{13} \mathrm{C}\right] 32$, pyridine $\left[{ }^{13} \mathrm{C}\right] 41$, pyrimidines $\left[{ }^{13} \mathrm{C}\right] 30$ and 2 -pyridone $\left[{ }^{13} \mathrm{C}\right] 28$.

Among current $\mathrm{CIE}$ technologies based on $\mathrm{CO}_{2}$ and $\mathrm{CO}$ exchange, none would be suitable for these bioactive compounds and, in the case of ester derivatives $\mathbf{3 0}$ and $\mathbf{3 1}$, they would require a series of additional saponification/esterification. The benefit is even more striking compared to traditional cyanating reactions, where the synthesis of the halogenated precursor is required.

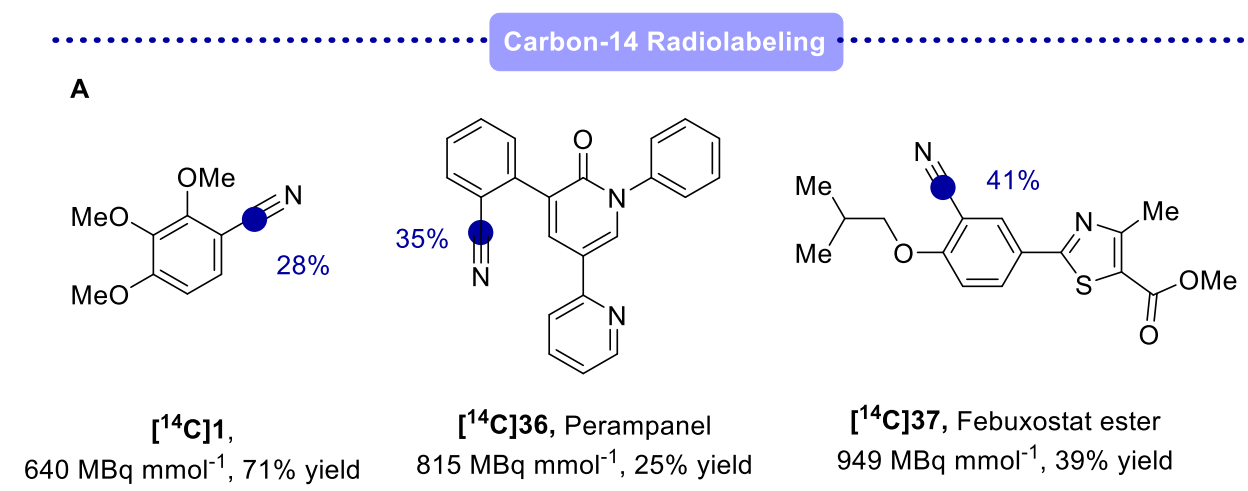

Fig 3. : Ni-catalyzed carbon-14 labeling.

To assess the utility of the nickel-catalyzed $\mathrm{CIE}$ over existing multistep methods, representative compounds were labeled using $\mathrm{Zn}\left[{ }^{14} \mathrm{C}\right] \mathrm{CN}_{2}$ (Fig. 3). Model substrate $\left[{ }^{14} \mathrm{C}\right] 1$, was obtained in $71 \%$ yield and molar activity of $\left(A_{m}\right) 640 \mathrm{MBq} \mathrm{mmol}^{-1}$. To widen its practicability, air-sensitive $\mathrm{Ni}(\mathrm{COD})_{2}$ was used in stoichiometric amounts avoiding requirement for radioactive-glovebox facilities. Perampanel $\left[{ }^{14} \mathrm{C}\right] 36$, an antiepileptic drug, was obtained with a $A_{m}$ of $815 \mathrm{MBq} \cdot \mathrm{mmol}^{-1}$ and $25 \%$ yield. Febuxostat methyl ester $\left[{ }^{14} \mathrm{C}\right] 37$ was labeled on the nitrile position with a molar activity of $949 \mathrm{MBq} \cdot \mathrm{mmol}^{-1}$, illustrating the complementarity of this method to the previously described $\mathrm{CIE}$ with $\left[{ }^{14} \mathrm{C}\right] \mathrm{CO}_{2} \cdot{ }^{12}$ Vilazodone $\left[{ }^{14} \mathrm{C}\right] 35$, a medication used to treat depressive disorders, was obtained with a molar activity of $540 \mathrm{MBq} \cdot \mathrm{mmol}^{-1}$. Finerenone is a nonsteroidal anti-mineralocorticoid agent for the treatment of chronic kidney diseases, whose full metabolic profile in dogs, rats and humans was recently disclosed by Bayer. ${ }^{14} \mathrm{C}$-Finerenone was labeled at the nitrile position by a multi-step procedure with an $A_{m}$ 
of $117 \mathrm{MBq} \cdot \mathrm{mmol}^{-1} \cdot{ }^{28}$ By means of this nickel-catalyzed $\mathrm{CIE},\left[{ }^{14} \mathrm{C}\right] 34$ was synthesized in a ten

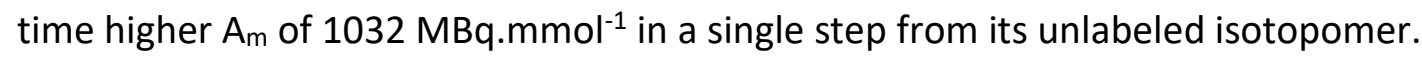

Based on previous literature on $\mathrm{C}-\mathrm{CN}$ bond cleavage, we suggest a catalytic cycle whereby, after an initial coordination of the metal to the nitrile, activation of benzonitrile occurs through oxidative addition onto a zerovalent $\mathrm{Ni}$ species, followed by nitrile isotope exchange. Subsequent reductive elimination delivers the desired labeled aromatic nitrile.

In summary, a nickel-catalysed nitrile isotope exchange procedure has been discovered. This reversible decyanation/cyanation technology bridges a gap in the state of the art, thus allowing for direct ${ }^{13} \mathrm{C}$ and ${ }^{14} \mathrm{C}$-labeling of nitrile derivatives. We anticipate that this methodology will accelerate access to new radiotracers suitable to support ADME studies and drug development. ${ }^{29}$

\section{ACKNOWLEDGMENT}

This work was supported by CEA and by the European Union's Horizon 2020 research and innovation program under the Marie Sklodowska-Curie grant agreement $\mathrm{N}^{\circ} 675071$ and the European Research Council (ERC-2019-COG - 864576). JDO is founded by a ANRT grant (CIFRE 2019/0914) with Sanofi. The authors thank A. Goudet, S. Lebrequier and D.-A. Buisson for the excellent analytical support.

\section{REFERENCES}

(1) Kamen, M. D., Early History of Carbon-14. Discovery of this supremely important tracer was expected in the physical sense but not in the chemical sense Science 1963, 140, 584-590.

(2) Isin, E. M.; Elmore, C. S.; Nilsson, G. N.; Thompson, R. A.; Weidolf, L., Use of Radiolabeled Compounds in Drug Metabolism and Pharmacokinetic Studies. Chem. Res. Toxicol. 2012, 25, 532-542.

(3) Penner, N.; Klunk, L. J.; Prakash, C., Human radiolabeled mass balance studies: objectives, utilities and limitations. Biopharm. Drug Dispos. 2009, 30, 185-203.

(4) Maxwell, B. D.: Elmore, C. S. in ADME-Enabling Technologies in Drug Design and Development. 461-471 (John Wiley \& Sons, Inc: Hoboken, 2012). (pp. 461-472 Wiley \& Sons, Inc 2012).

(5) Elmore, C. S. in The Use of Isotopically Labeled Compounds in Drug Discovery. Ed. Annu. Rep. Med. Chem. 2009, 44, 515-534.

(6) Voges, R.; Heys, J. R.; Moenius, T. Preparation of Compounds Labeled with Tritium and Carbon-14 (John Wiley \& Sons, 2009). 
(7) ${ }^{14} \mathrm{C}$ is generated as $\mathrm{Ba}\left[{ }^{14} \mathrm{C}\right] \mathrm{CO}_{3}$, routinely converted to carbon dioxide $\left[{ }^{14} \mathrm{C}\right] \mathrm{CO}_{2}$, as primary source, see: Zwiebel, N.; Turkevich, J.; Miller, W. W. Preparation of Radioactive $\mathrm{CO}_{2}$ from $\mathrm{BaCO}_{3}$. J. Am. Chem. Soc., 1949, 71, 376-377. Other $\mathrm{CO}_{2}$-derived primary building blocks are $\mathrm{K}^{14} \mathrm{CN}$ and ${ }^{14} \mathrm{CH}_{3}$.

(8) Atzrodt, J.; Derdau, V.; Loewe, C. in Drug Discovery and Evaluation: Methods in Clinical Pharmacology, F. J. Hock, M. R. Gralinski, Eds. (Springer International Publishing, Cham, 2017), pp. 1-19.

(9) a) Donslund, A. S.; Pedersen, S. S.; Gaardbo, C.; Neumann, K. T.; Kingston, L.; Elmore, C. S.; Skrydstrup, T., Direct Access to Isotopically Labeled Aliphatic Ketones Mediated by Nickel(I) Activation. Angew. Chem. Int. Ed. 2020, 59, 8099-8103. b) Del Vecchio, A.; Caillé, F.; Chevalier, A.; Loreau, O.; Horkka, K.; Halldin, C.; Schou, M.; Camus, N.; Kessler, P.; Kuhnast, B.; Taran, F.; Audisio, D., Late-Stage Isotopic Carbon Labeling of Pharmaceutically Relevant Cyclic Ureas Directly from $\mathrm{CO}_{2}$. Angew. Chem. Int. Ed. 2018, 57, 9744-9748. c) Pipal, R. W.; Stout, K. T.; Musacchio, P. Z.; Ren, S.; Graham, T. J. A.; Verhoog, S.; Gantert, L.; Lohith, T. G.; Schmitz, A.; Lee, H. S.; Hesk, D.; Hostetler, E. D.; Davies, I. W.; MacMillan, D. W. C., Metallaphotoredox aryl and alkyl radiomethylation for PET ligand discovery. Nature 2021, 589, 542-547.

(10) Hinsinger, K.; Pieters, G., The Emergence of Carbon Isotope Exchange. Angew. Chem. Int. Ed. 2019, 58, 9678-9680.

(11) a) Kingston, C.; Wallace, M. A.; Allentoff, A. J.; deGruyter, J. N.; Chen, J. S.; Gong, S. X.; Bonacorsi, S.; Baran, P. S., Direct Carbon Isotope Exchange through Decarboxylative Carboxylation. J. Am. Chem. Soc. 2019, 141, 774-779. b) Tortajada, A.; Duan, Y.; Sahoo, B.; Cong, F.; Toupalas, G.; Sallustrau, A.; Loreau, O.; Audisio, D.; Martin, R., Catalytic Decarboxylation/Carboxylation Platform for Accessing Isotopically Labeled Carboxylic Acids. ACS Catal. 2019, 9, 5897-5901.

(12) Destro, G.; Loreau, O.; Marcon, E.; Taran, F.; Cantat, T.; Audisio, D., Dynamic Carbon Isotope Exchange of Pharmaceuticals with Labeled $\mathrm{CO}_{2}$. J. Am. Chem. Soc. 2019, 141, 780-784.

(13) a) Destro, G.; Horkka, K.; Loreau, O.; Buisson, D.-A.; Kingston, L.; Del Vecchio, A.; Schou, M.; Elmore, C. S.; Taran, F.; Cantat, T.; Audisio, D., Transition-Metal-Free Carbon Isotope Exchange of Phenyl Acetic Acids. Angew. Chem. Int. Ed. 2020, 59, 13490-13495. b) Kong, D.; Moon, P. J.; Lui, E. K. J.; Bsharat, O.; Lundgren, R. J., Direct reversible decarboxylation from stable organic acids in dimethylformamide solution. Science 2020, 369, 557-561.

(14) a) Babin, V.; Talbot, A.; Labiche, A.; Destro, G.; Del Vecchio, A.; Elmore, C. S.; Taran, F.; Sallustrau, A.; Audisio D. A Photochemical Strategy for Carbon Isotope Exchange with $\mathrm{CO}_{2}$. ACS Catal. 2021 : DOI : 10.1021/acscatal.0c05344. b) Kong, D.; Munch, M.; Qiqige, Q.; Cooze, C. J. C.; Rotstein, B. H.; Lundgren, R. J., Fast Carbon Isotope Exchange of Carboxylic Acids Enabled by Organic Photoredox Catalysis. J. Am. Chem. Soc. 2021, 143, 2200-2206.

(15) Gauthier, D. R.; Rivera, N. R.; Yang, H.; Schultz, D. M.; Shultz, C. S., Palladium-Catalyzed Carbon Isotope Exchange on Aliphatic and Benzoic Acid Chlorides. J. Am. Chem. Soc. 2018, 14, 15596-15600. 
(16) Science of Synthesis; Murahashi, S.-I., Ed.; Georg Thieme Verlag: Stuttgart, Germany, 2004; Vol. 19.

(17) Fleming, F. F.; Yao, L.; Ravikumar, P. C.; Funk, L.; Shook, B. C., Nitrile-Containing Pharmaceuticals: Efficacious Roles of the Nitrile Pharmacophore. J. Med. Chem. 2010, 53, 7902-7917.

(18) Derdau, V., New trends and applications in cyanation isotope chemistry. J. Label. Compd Radiopharm. 2018, 61, 1012-1023.

(19) Tobisu, M.; Chatani, N., Catalytic reactions involving the cleavage of carbon-cyano and carbon-carbon triple bonds. Chem. Soc. Rev. 2008, 37, 300-307. For comparison, C-Br bond dissociation energy is $\sim 80 \mathrm{kcal} / \mathrm{mol}$.

(20) a) Nakao Y. (2014) Catalytic C-CN Bond Activation. In: Dong G. (eds) C-C Bond Activation. Topics in Current Chemistry, vol 346. Springer, Berlin, Heidelberg. https://doi.org/10.1007/128_2013_494. b) Nakao, Y., Metal-mediated C-CN Bond Activation in Organic Synthesis. Chem. Rev. 2021, 121, 327-344. c) Nájera, C.; Sansano, J. M., Asymmetric Intramolecular Carbocyanation of Alkenes by C-C Bond Activation. Angew. Chem. Int. Ed. 2009, 48, 2452-2456.

(21) a) Wen, Q.; Lu, P.; Wang, Y., Recent advances in transition-metal-catalyzed C-CN bond activations. RSC Adv. 2014, 4, 47806-47826. b) Bonesi, S. M.; Fagnoni, M., The Aromatic Carbon-Carbon ipso-Substitution Reaction. Chem. Eur. J. 2010, 16, 13572-13589.

(22) Anbarasan, P.; Schareina, T.; Beller, M., Recent developments and perspectives in palladium-catalyzed cyanation of aryl halides: synthesis of benzonitriles. Chem. Soc. Rev. 2011, 40, 5049-5067.

(23) Jones, L. H.; Summerhill, N. W.; Swain, N. A.; Mills, J. E., Aromatic chloride to nitrile transformation: medicinal and synthetic chemistry. MedChemComm 2010, 1, 309-318.

(24) For examples of transfer hydrocyanation, see : a) Bhawal, B. N.; Morandi, B., A Reversible, Transfer Hydrocyanation Manifold. Trends Chem. 2020, 2, 1034-1035. b) Bhawal, B. N.; Reisenbauer, J. C.; Ehinger, C.; Morandi, B., Overcoming Selectivity Issues in Reversible Catalysis: A Transfer Hydrocyanation Exhibiting High Kinetic Control. J. Am. Chem. Soc. 2020, 142, 10914-10920. c) Yu, P.; Morandi, B., Nickel-Catalyzed Cyanation of Aryl Chlorides and Triflates Using Butyronitrile: Merging Retro-hydrocyanation with Cross-Coupling. Angew. Chem. Int. Ed. 2017, 56, 15693-15697.

(25) At equilibrium, theoretically the ratio $\left[{ }^{13} \mathrm{CN}\right]:\left[{ }^{12} \mathrm{CN}\right]=1.3: 1$, in reaction system.

(26) When higher amounts of $\mathrm{Zn}\left[{ }^{13} \mathrm{C}\right] \mathrm{CN}_{2}$ were utilized, we did not observe improvement in the isotope enrichment. On the opposite, the afficiecy of the reaction decreses. This results further support the hypothesis of catalyst poisoning. See supporting information for details.

(27) Tsuei, M.; Shivrayan, M.; Kim, Y.-K.; Thayumanavan, S.; Abbott, N. L., Optical "Blinking" Triggered by Collisions of Single Supramolecular Assemblies of Amphiphilic Molecules with Interfaces of Liquid Crystals. J. Am. Chem. Soc. 2020, 142, 6139-6148. 
(28) Gerisch, M.; Heinig, R.; Engelen, A.; Lang, D.; Kolkhof, P.; Radtke, M.; Platzek, J.; Lovis, K.; Rohde, G.; Schwarz, T., Biotransformation of Finerenone, a Novel Nonsteroidal Mineralocorticoid Receptor Antagonist, in Dogs, Rats, and Humans, In Vivo and In Vitro. Drug Metab. Dispos. 2018, 46, 1546-1555.

(29) While this work was submitted, an analogous study was uploaded as preprint : Reilly, S.; Lam, Y.-H.; Ren, S.; Strotman, N. Late-Stage Carbon Isotope Exchange of Aryl Nitriles through Ni-Catalyzed C-CN Bond Activation. ChemRxiv. 2021, Preprint. ttps://doi.org/10.26434/ chemrxiv.13724023.v2 